\title{
Determination Method of Critical Best Tip Speed Ratio for the Vertical Axis Wind Turbine
}

\author{
Zhang Lijun ${ }^{*}, 1$, Liu Hua ${ }^{2}$, Zhang Mingming ${ }^{2}$ and Hu Yi’ ${ }^{2}$ \\ ${ }^{I}$ College of Mechanical and Electronic Engineering, China University of Petroleum, Qingdao, Shandong, 266580, P.R. \\ China \\ ${ }^{2}$ Qingdao Donghua Shi Intelligent Equipment Co., Ltd, Qingdao, Shandong, 266580, P.R. China
}

\begin{abstract}
Tip speed ratio is an important parameter of describing wind turbine performance. Based on vane airfoil profile, the relationship between vane lift coefficient, drag coefficient and angle of attack is calculated by means of Profili software. The corresponding stall angle is also obtained. The relationship between the position angle of vane and angle of attack at different tip speed ratios is drawn by Matlab software and the corresponding best tip speed ratio is determined rapidly. Based on it, the airfoil tangential force is also analyzed for different vane airfoil profiles in the condition of same Reynolds number.
\end{abstract}

Keywords: Vertical axis wind turbine (VAWT), Tip speed ratio, Airfoil profile, Profili, Stall angle.

\section{INTRODUCTION}

According to the development history of wind turbine, compared with the horizontal axis wind turbine, the outstanding superiority, relative lag of technology development level and low market share rate of MW wind machine have been the present situation of vertical axis wind turbine, and have also become the developmental difficulties of vertical axis wind turbine. However, above these perhaps are also the motive powers of development [1].

The vertical axis wind turbine has the following characteristics: it does not need to adjust the direction of the wind, and its generator, gear boxes and other equipment can be placed on the ground, and so on, and it greatly overcomes the inherent structure defects of horizontal axis wind turbine, which will become the development trend of high efficiency wind turbine. However, the present vertical axis wind turbine is not applied in commercial production on a large scale in the whole world but it mainly exists in the small and medium-sized market, which generally is caused by the following so-called perspectives: study on the basic theory of vertical axis wind turbine is far less than the horizontal axis wind turbine; coefficient of wind energy utilization of traditional vertical axis wind turbine is lower than one of the horizontal axis wind turbines; and start-up of vertical axis wind turbine is more difficult and it cannot be self-starting [1].

The angle of attack of vane is a key factor to influence the characteristic of wind turbine. The tip speed ratio directly reflects the angle between the relative wind speed and movement direction of vane, which is the angle of attack of

*Address correspondence to this author at the College of Mechanical and Electronic Engineering, China University of Petroleum, Qingdao, Shandong, 266580, P.R. China; Tel: 053286983500;

E-mail: zlj1977628@sohu.com vane. At the same time, the tip speed ratio is also an important basis for designing the vane height, wind wheel diameter and other parameters. At present, for the representative vane, the lift coefficient and the drag coefficient, by which the tip speed ratio is calculated, can be obtained only through published data access. For the airfoil profile of vane designed by ourselves, it is very difficult to obtain its tip speed ratio, and can be determined only by wind tunnel test [2-4]. By means of Profile software, a method of calculating the tip speed ratio for airfoil profile of vane of lift type vertical axis wind turbine designed by ourselves is proposed in this paper. Based on vane airfoil profile, the relationship between lift coefficient and drag coefficient and angle of attack is calculated out by means of Profili software. The corresponding stall angle is also obtained. Based on it, the relationship between the position angle of vane and angle of attack at the different tip speed ratio is drawn and then the corresponding best tip speed ratio is determined. This is a great help in designing the corresponding wind wheel structure and get the maximum wind energy.

\section{DEFINITION OF TIP SPEED RATIO OF VERTICAL AXIS WIND TURBINE}

The wind speed divided by the tip speed (circumferential speed) of vane is called the tip speed ratio, and its expression is

$\Lambda=\frac{u}{v}=\frac{w R}{v}=\frac{2 \pi n R}{60 v}$

where $u$ is the linear velocity of the tip of vane, $\mathrm{m} / \mathrm{s} ; n$ is the rotational speed, $\mathrm{r} / \mathrm{min} ; v$ is the wind speed, $\mathrm{m} / \mathrm{s} ; R$ is the rotation radius of wind wheel, $\mathrm{m}$. It can be seen from equation (1), the longer the vane is, or the higher the 
rotational speed of vane is, then the greater the tip speed ratio is at the same wind speed.

\section{CALCULATION OF CRITICAL MINIMUM TIP SPEED RATIO OF VERTICAL AXIS WIND TURBINE}

\subsection{Drawing of Vane Airfoil Profile}

At first, by means of related theory and drawing software such as autoCAD, Visio, Solidworks, the vane airfoil profile designed by ourselves is drawn out. And then these graphics are converted into bmp, gif, tif or other feasible formats. A kind of vane airfoil profile $\mathrm{zx}$ drawn by autoCAD software is shown in Fig. (1).

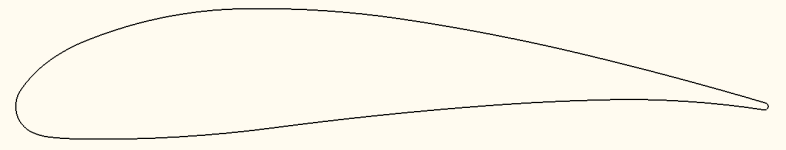

Fig. (1). Curve skeleton map of vane.

\subsection{Calculation of Lift Coefficient and Drag Coefficient of Vane}

According to ProfiliV2.21 software, the above curve skeleton map is input into the software by airfoil profile management window. Then click the button with the same vane and different Reynolds number in $\mathrm{P}$ pole line, and then the relationship between vane lift coefficient and drag coefficient and angle of attack for the asymmetry vane airfoil profile is shown in Fig. (2). As shown in Fig. (2), the stall angle of this vane is about 13 degrees and here lift coefficient descends markedly and drag coefficient ascends observably. In addition, it is also shown that the stall angle of this vane is small, lift coefficient is small and the drag coefficient is big when the Reynolds number of vane is small.

\subsection{Relationship Between Position Angle and Angle of Attack of Vane Under the Condition of Different Tip Speed Ratio}

The correlative angle graphics of vane is shown in Fig. (3). By means of this figure, the angle of attack of vane at the different position can be obtained. According to aerodynamics, the link of the leading edge and the trailing edge of vane is called chord line. The angle between the chord line and the tangent line at a circumference position is called the rotation angle of vane, namely angle c in Fig. (3). The angle between the chord line and the relative wind speed is called angle of attack, namely angle a in Fig. (3). The angle between the link of rotating center and aerodynamic center and 0 degree line in coordinate system is called position angle of vane, namely angle $b$ in Fig. (3).
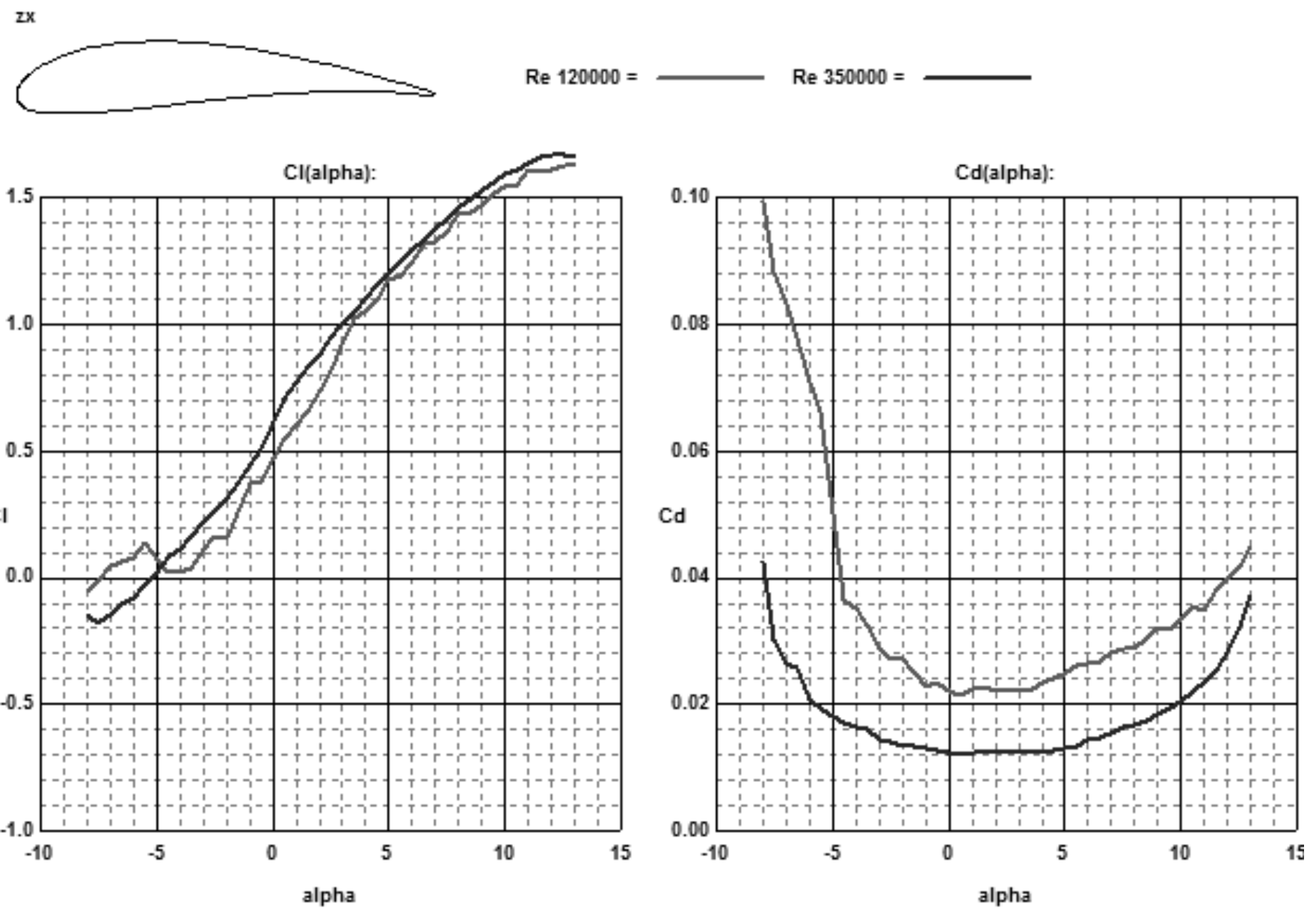

Fig. (2). Relationship between vane lift coefficient and drag coefficient and angle of attack for asymmetry vane airfoil profile. 
Taking the vane with a position angle of 90 degrees as an example, the following equation can be obtained:

$\tan (a+c)=\frac{x}{u+y}=\frac{v \sin b}{u+v \cos b}$

Therefore, the angle of attack of vane can be calculated from the equation(2).

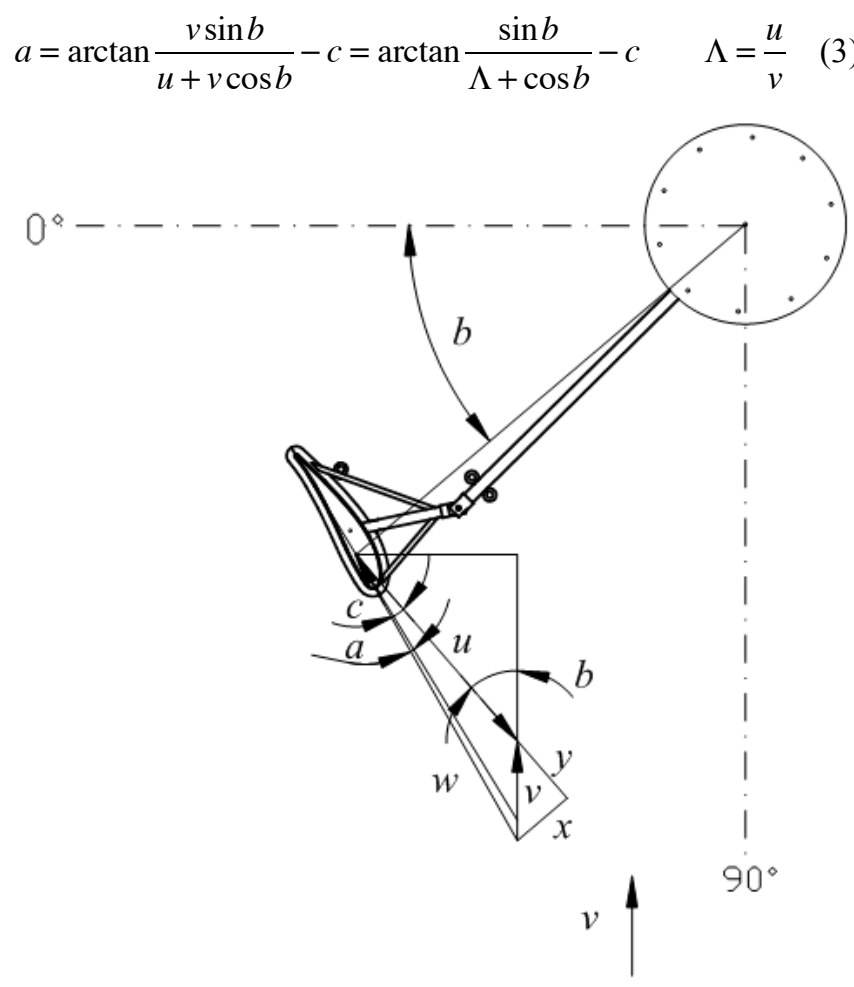

Fig. (3). The correlative angle graphics of vane.

By means of Matlab software, the relationship between the position angle of vane and angle of attack at different tip speed ratio is shown in Fig. (4) when the rotation angle of vane is equal to 9.5 degrees. As shown in Fig. (4), the maximal angle of attack (Stall angle) is equal to about 13 degrees when the tip speed ratio is 2.4 .

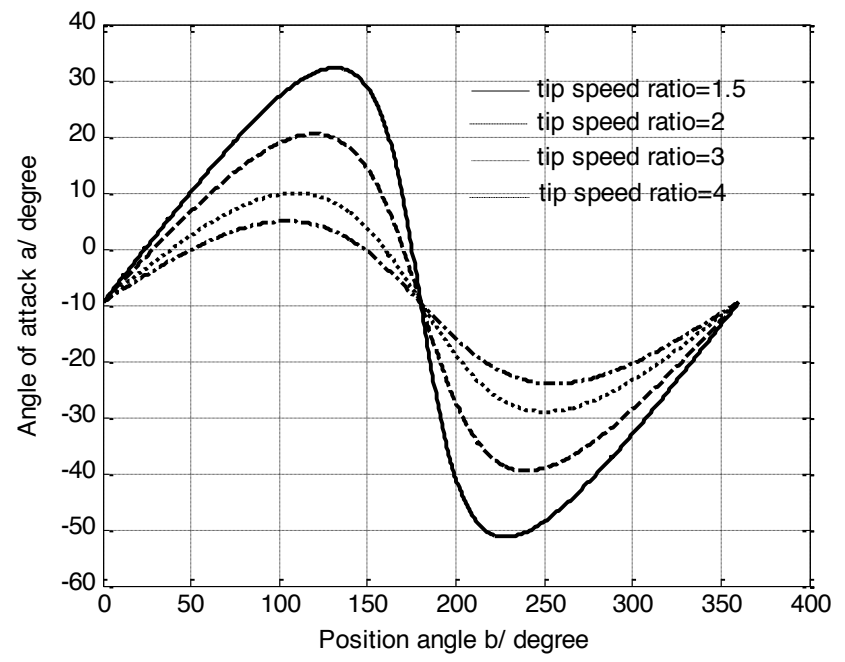

Fig. (4). Relationship between the position angle and angle of attack of vane at different tip speed ratio.

\section{ANALYSIS OF TANGENTIAL FORCE OF DIFFERENT AIRFOIL PROFILE WITH THE SAME REYNOLDS NUMBER}

Besides the ratio of lift coefficient $C_{\mathrm{L}}$ to drag coefficient $C_{\mathrm{d}}$ can be used to determine the stall angle of vane, $C_{\mathrm{L}} / C_{\mathrm{d}}$ can also judge the ability of vane promoting the wind wheel rotation. The tangential force of airfoil profile refers to the force of tangent direction of lift and drag on the rotating circumference of airfoil profile, and the force is also the force of promoting the wind wheel rotation. The calculation of auxiliary graph of tangential force of airfoil profile with a position angle of 90 degrees is shown in Fig. (5). The relationship between the $C_{\mathrm{L}} / C_{\mathrm{d}}$ and angle of attack at the same Reynolds number for airfoil profile $\mathrm{zx}$ and common airfoil profile NACA0012 is obtained and shown in Fig. (6) by Profili software. As shown in Fig. (6), the $C_{\mathrm{L}} / C_{\mathrm{d}}$ curve for symmetrical airfoil profile NACA0012 usually goes through the origin of coordinate system, and the $C_{\mathrm{L}} / C_{\mathrm{d}}$ curve for asymmetric airfoil profile $\mathrm{zx}$ is a positive value when the angle of attack is equal to zero. At the same angle of attack, $C_{\mathrm{L}} / C_{\mathrm{d}}$ of asymmetric airfoil profile $\mathrm{zx}$ is greater than one of symmetrical airfoil profile NACA0012 before the stall angle. In addition, the stall angle of asymmetric airfoil profile is less than one of symmetrical airfoil profiles.

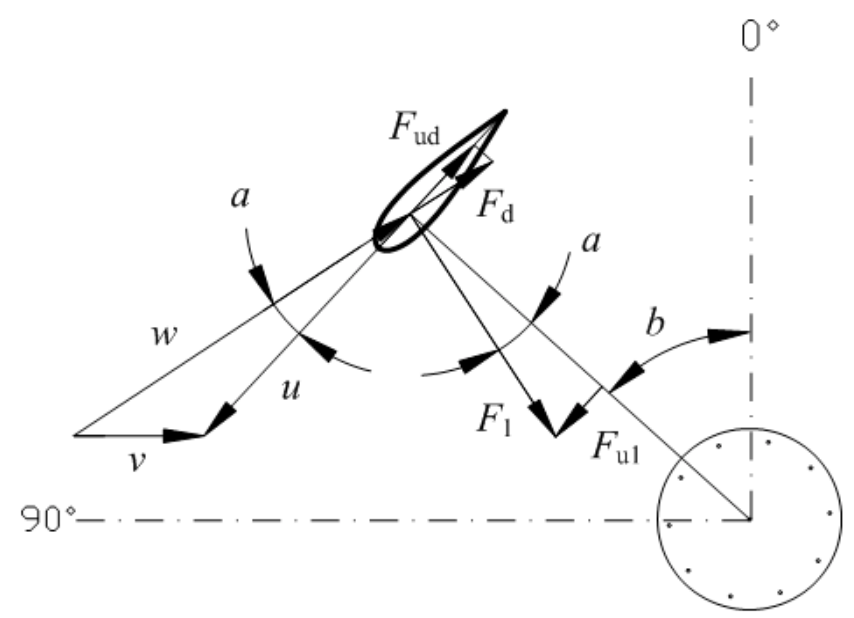

Fig. (5). The auxiliary graph of calculation of tangential force of airfoil profile with a position angle of 90 degrees.

\section{THE DETERMINATION OF THE ACTUAL TIP SPEED RATIO OF VERTICAL AXIS WIND TURBINE VANE}

The above obtained tip speed ratio is a theoretical result when only considering the airfoil profile of vane, which does not consider the influence of some factors such as the wind wheel structure and transmission system. According to equation (1), when computing the tip speed ratio of vane, the relationship between the wind speed and the corresponding rotating speed of wind wheel is determined if the rotation radius of the wind wheel is known. However, for the wind turbine system with the tip speed ratio obtained by the above theory, the actual rotating speed of wind wheel is lower than the theoretical rotating speed at the same wind speed, namely, the tip speed ratio of actual measurement is smaller 


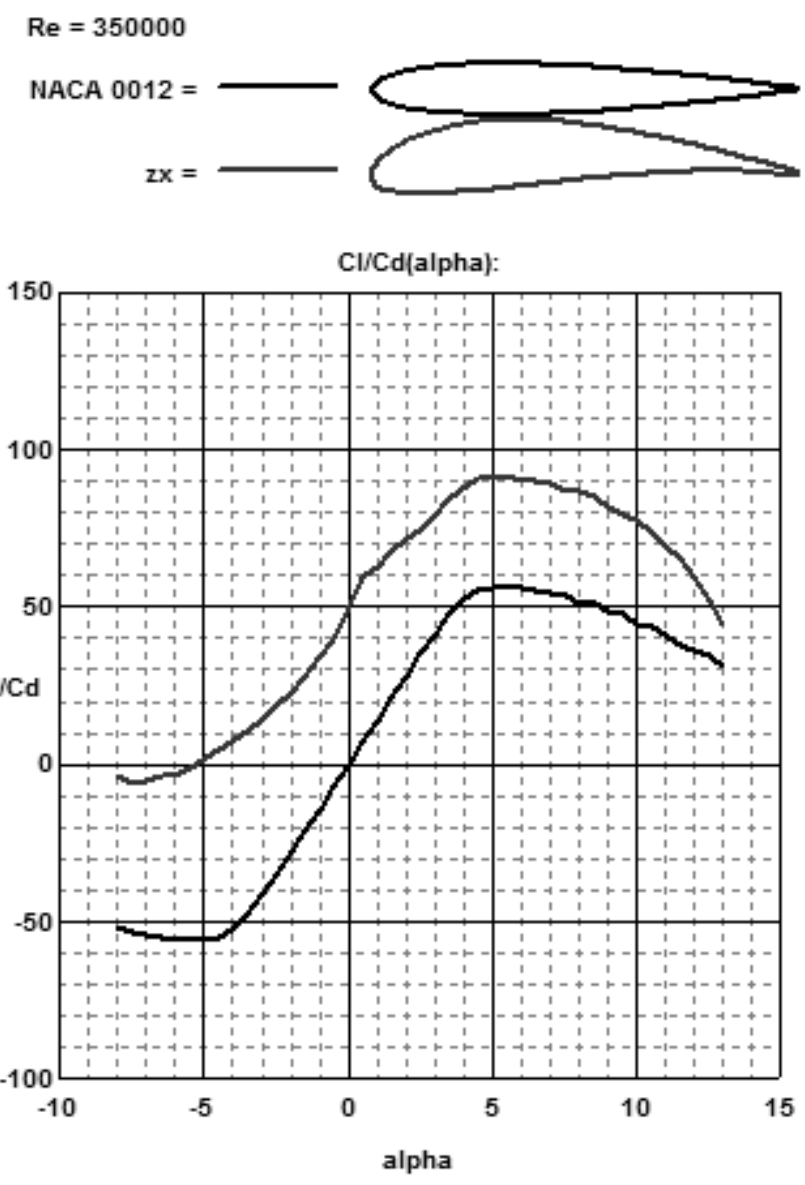

Fig. (6). Relationship between the $C_{\mathrm{L}} / C_{\mathrm{d}}$ and angle of attack at the same Reynolds number for airfoil profile $\mathrm{zx}$ and common airfoil profile NACA0012.

than the calculated one. This is because that the rotating speed of wind wheel is affected by some factors such as mechanical transmission efficiency and power efficiency, although the wind speed is certain. Therefore, for the wind turbine system with the mechanical and electrical energy conversion device including mechanical gear box, permanent magnet generator and so on, usually the actual tip speed ratio should be $60 \% \sim 75 \%$ of theoretical tip speed ratio. Based on it, the relationship between the wind speed and rotating speed of wind wheel can be determined. For the wind turbine system with the mechanical and electrical energy conversion device using hydraulic system and the common generator, usually the actual tip speed ratio should be $45 \% \sim 65 \%$ of theoretical tip speed ratio. In general, for the lift type vertical axis wind turbine vane, the actual tip speed ratio is usually between 1.2 2.

\section{CONCLUSION}

\section{CONFLICT OF INTEREST}

The author confirms that this article content has no conflict of interest.

\section{ACKNOWLEDGEMENTS}

The author wishes to express gratitude to the Fundamental Research Funds for the Central Universities (Approval no. 14CX02069A, 12CX02009A) and Qingdao Development Zone Science and Technology Development Project (approval no. 2014-1-47, 2014-1-20), which have supported this work.

\section{REFERENCES}

[1] I. Paraschivoiu, Principle and design of vertical axis wind turbine. Translation, L. Chun, Y. Zhou, G. Wei, Eds. ShangHai: Shanghai science and Technology Press, 2013, pp.1-10.

[2] K.O. Jiro, Design and manufacture of small wind turbine, Translation: Y. Xingjia, W. Yiquan. Eds. Beijing: Science Press, 2012.

[3] Z. Du, L. Ma, Wind power generation, Beijing: Chemical Industry Press, 2009, pp. 10-25.

[4] D. Greenblatt, M. Schulman, A. Ben-Harav, "Vertical axis wind turbine performance enhancement using plasma actuators", Renewable Energy, vol. 37, pp. 345-354, 2012. 